\title{
Anion-binding aromatic pentaamide macrocycles: Synthesis, high-affinity binding, transmembrane transport, and catalysis
}

\section{Ruikai Cao}

University at Buffalo, State University of New York

\section{Robert Rossdeutcher}

University at Buffalo, The State University of New York

\section{Yi Shen}

Shanghai Jiao Tong University

\section{Daniel Miller}

Hofstra University https://orcid.org/0000-0003-1507-2667

\section{Yulong Zhong}

University at Buffalo, State University of New York

\section{Laura Sánchez B.}

Hofstra University

Karishma Ramcharan

Hofstra University

\section{Xiangxiang Wu}

Beijing Normal University

\section{Eva Zurek}

SUNY Buffalo https://orcid.org/0000-0003-0738-867X

\section{Thomas Szyperski}

State University of New York at Buffalo

\section{Zhifeng Shao}

Shanghai Jaio Tong University

Bing Gong ( $\sim$ bgong@buffalo.edu )

University at Buffalo, State University of New York https://orcid.org/0000-0002-4155-9965

\section{Article}

\section{Keywords:}

Posted Date: February 4th, 2022 
License: (c) (i) This work is licensed under a Creative Commons Attribution 4.0 International License. Read Full License 


\section{Anion-binding aromatic pentaamide macrocycles: 2 Synthesis, high-affinity binding, transmembrane 3 transport, and catalysis}

Ruikai Cao, ${ }^{1, \#}$ Robert B. Rossdeutcher, ${ }^{1 \#}$ Yi Shen, ${ }^{2}$ Daniel P. Miller, ${ }^{3}$ Yulong Zhong, ${ }^{1}$ Laura S. Sánchez B., ${ }^{3}$ Karishma Ramcharan, ${ }^{3}$ Xiangxiang Wu, ${ }^{4}$ Eva Zurek, ${ }^{1}$ Thomas Szyperski, ${ }^{1}$ Zhifeng Shao ${ }^{2, *}$ and Bing Gong ${ }^{1, *}$

${ }^{1}$ Department of Chemistry, University at Buffalo, The State University of New York, Buffalo, New York 14260, USA

$11{ }^{2}$ School of Biomedical Engineering, Shanghai Jiao Tong University, Shanghai 200240, China

$12{ }^{3}$ Department of Chemistry, Hofstra University, Hempstead, NY 11549, USA

$13{ }^{4}$ Academy of Chinese Medical Science, Henan University of Chinese Medicine, 156 Jinshui East Road,

14 Zhengzhou, 450046, Henan, China

The precise spatial positioning of functional groups in biomacromolecules leads to astonishing binding, catalytic, and transport capabilities. In contrast, synthetic frameworks capable of convergently locking functional groups with minimized conformational uncertainty are highly desirable but rare. Here we report $C_{5}$-symmetric aromatic pentaamide macrocycles c5a-c synthesized in one pot from the corresponding monomers. The crystal structure of $c 5 c$ reveals a fully constrained backbone that enforces ten alternating $\mathrm{NH} / \mathrm{CH}$ hydrogen-bond donors and five large amide dipoles to point to the center of the macrocycle. With a highly electropositive cavity in a high-energy unbound state, macrocycles $c 5$ bind anions in a 1:1 stoichiometry in solution, with $K_{\mathrm{a}}$ values up to $10^{7} \mathrm{M}^{-1}$ for halides and $10^{8} \mathrm{M}^{-1}$ for oxoanions. Macrocycle c5a was able to selectively transport chloride ions across lipid bilayers. The extraordinary binding of phosphaterelated ions by $\mathrm{c} 5$ also enabled catalytic ester amidation owing to the stabilization of the corresponding transition states.

Molecular and supramolecular structures with multiple functional groups being convergently placed at defined positions occur ubiquitously in nature ${ }^{1}$. By amassing multiple noncovalent forces ${ }^{2,3}$, such structures exhibit sophisticated functions ranging from ligand binding and catalysis to mass transport and signal transduction that are still beyond the reach of synthetic constructs. For example, with a "selectivity filter" defined by aligned polar groups and dipoles, the potassium channel $\mathrm{KcsA}^{4}$ or the water channel aquaporin $1^{5}$ achieves astounding efficiency and exclusive selectivity in transporting potassium ions or water molecules. The remarkable power of convergent functional groups is also demonstrated by many ligand39 binding proteins such as the sulfate-binding protein (SBP) from the gram-negative bacterium $S$. 
typhimurium $^{6}$. SBP binds the sulfate ion, an anion with a large hydration enthalpy $(-258 \mathrm{kcal} / \mathrm{mol})$, in high affinity $\left(K_{\mathrm{a}}=8.3 \times 10^{6} \mathrm{M}^{-1}\right.$ at $\left.\mathrm{pH} 8.3\right)$ in water. By forming seven neutral hydrogen bonds with the sulfate ion, five involving the main chain peptide $\mathrm{NH}$ groups, one with a serine $\mathrm{OH}$ and another with the indole $\mathrm{NH}$ of a tryptophan residue, SBP demonstrates that neutral hydrogen bonds, if properly placed, can result in extraordinary binding affinity for an anion.

As a major class of guests, anions have attracted wide interest in molecular recognition because of their important roles in biology, medicine, catalysis, and the environment ${ }^{7}$. In contrast to cations, anions, with a variety of sizes and shapes, are challenging targets that remained a largely elusive species for synthetic receptors until recent years ${ }^{8}$. Anion recognition requires the convergent alignment of binding groups, especially hydrogen-bond donors. So far, typical anion receptors include linear or branched molecules carrying hydrogen-bond donors based on the NH groups of amides, ureas, pyrroles, amines, and ammoniums ${ }^{9}$. More recently, systems based on halogen bonds were also reported ${ }^{10-12}$. With such hosts, the entropic costs for hydrogen-bond donors to converge on anions have to be compensated by the enthalpic gains from multiple non-covalent interactions ${ }^{13}$.

Efforts on arranging convergent functional groups with synthetically accessible structures have continued for quite a long time. A highly effective strategy for converging multiple functional groups is macrocycles ${ }^{12-25}$. Such structures exhibit unique and often remarkable properties including selective and tight binding of guest species.

Shape-persistent macrocycles are especially powerful in converging functional groups and generating non-deformable cavities with defined sizes, based on which anion binders featuring high binding affinity and selectivity could be created. A rigid macrocycle reported by Flood et al. forms stable 2:1 sandwich complexes with large anions by orienting convergent cyanostilbene and phenyl $\mathrm{CH}$ groups ${ }^{26}$. Another rigid macrocycle having convergent triazole and phenyl $\mathrm{CH}$ groups, also developed by Flood et al., binds the chloride ion $\left(K_{\mathrm{a}}=1.3 \times 10^{5} \mathrm{M}^{-1}\right.$ in $\left.\mathrm{CH}_{2} \mathrm{Cl}_{2}\right)$ with a $1: 1$ stoichiometry ${ }^{27}$. These systems, along with other examples such as those reported by Anslyn ${ }^{28}$, Sessler ${ }^{25,29}$, and Gale ${ }^{30}$, demonstrate that rigid cyclic hosts with convergently organized hydrogen-bond donors, even those involving aromatic $\mathrm{CH}$ groups which are regarded as "weak" donors, can still achieve strong overall binding for anions.

Among hydrogen-bond donors, the amide NH functionality, with its exceptional hydrogen-bonding capability and ready synthetic accessibility, is much preferred in the design of synthetic anion receptors ${ }^{31,32}$. Aromatic oligoamide macrocycles, with backbones comprised of aromatic residues linked by amide linkages, have persistent shapes that can recruit multiple binding elements together in a rigid relationship amenable to strong anion binding. Ideally, the backbones of such oligoamide macrocycles should not only be rigid but also be fully constrained, i.e., even rotation around each backbone aryl-amide single bonds should be hindered, so that local orientational ambiguity associated with the amide groups may be restricted or even eliminated. However, due to the structural limitations of the amide group, most known amide-based anion receptors have global to local conformational flexibility that has compromised both binding affinity and selectivity. In addition, incorporating amide $\mathrm{NH}$ units into anion receptors inevitably brings along amide $\mathrm{C}=\mathrm{O}$ groups that incur undesired hydrogen-bonding interactions, leading to self-aggregation and poor solubility. As a result, few anion binders based on shape-persistent oligoamide macrocycles are known thus far. 
Hamilton et al. published their seminal work on a rigid aromatic triamide macrocycle that projects three NH groups in a cavity of $\sim 5 \AA$ across and binds dihydrogen phosphate strongly $\left(K_{\mathrm{a}} \approx 10^{4} \mathrm{M}^{-1}\right.$ in DMSO- $\left.d_{6}\right)$

33. This macrocycle, however, has a backbone in which the rotation of aryl-amide single bonds is not restricted. Consequently, either the $\mathrm{C}=\mathrm{O}$ or the $\mathrm{N}-\mathrm{H}$ group of a backbone amide linkage may point to the center of the macrocycle. While we have succeeded in construct aromatic oligoamide macrocycles with backbone amide $\mathrm{C}=\mathrm{O}$ groups being rigidly placed into a convergent orientation ${ }^{20}$, the inherent limitation of the amide group still precludes the creation of rigid aromatic oligoamide macrocycles capable of locking convergent $\mathrm{NH}$ groups for anion-binding. In fact, the creation of rigid hosts with binding sites containing only amide $\mathrm{NH}$ and phenyl $\mathrm{CH}$ groups as preorganized hydrogen-bond donors for anion binding remains a daunting conceptual and synthetic challenge with few feasible solutions. To address this challenge, we have now successfully designed and synthesized aromatic pentaamide macrocycles $\mathbf{c 5}$ featuring a constrained backbone that, for the first time, locks multiple amide $\mathrm{NH}$ and $\mathrm{CH}$ groups into an unequivocally convergent placement. The non-deformable cavity of $\mathbf{c 5}$ defined by these $\mathrm{NH}$ and $\mathrm{CH}$ donors, along with the positive ends of large amide dipoles that also point inward, is highly electropositive and predisposed for anion accommodation.

\section{Results and discussion}

98 Design of cyclic aromatic pentaamides c5 featuring a fully constrained cyclic backbone with locked endocyclic CH and NH donors. We recently reported a series of anion-binding aromatic oligoamide foldamers sharing general structure 1 (Fig. 1a) ${ }^{35}$. The intramolecular hydrogen bonds incorporated into 1 serve to (1) partially rigidify the oligoamide backbone, (2) prevent the backbone amide $\mathrm{C}=\mathrm{O}$ groups from engaging in additional H-bonding interaction, and (3) free the backbone amide NH groups to form hydrogen bonds with guest species. As shown in Fig. 1a, amide 1a, i.e., the basic unit of 1, has a large dipole moment (4.24 D) contributed by the two hydrogen-bonded amide groups, while amide $\mathbf{1 b}$, which lacks a sidechain amide group, has a smaller dipole moment $(3.28 \mathrm{D})$. Thus, oligoamides 1 adopt a conformation in which the adjacent amide dipoles align in an energetically favorable antiparallel orientation. Similar to the handful of currently known anion-binding foldamers ${ }^{22,37-40}$, oligoamides 1 , upon binding an anion, fold into conformation 1crs in which the backbone NH groups, along with the positive ends of the amide dipoles, are oriented to define an electropositive cavity ${ }^{35}$. The entropic barrier for $\mathbf{1}$ to adopt conformation 1 crs leads to modest anion binding affinities that are proportional to the number of $\mathrm{NH}$ groups ${ }^{35}$.

Cyclizing oligoamides 1 yields the corresponding macrocycles. Based on the bond angles defined by the $112 s p^{2}$-hybridized $\mathrm{C}$ and $\mathrm{N}$ atoms constituting the oligoamide backbone, macrocycles with five or six residues are most likely to form. Other smaller or larger macrocycles will be more strained and thus be more difficult

114 to make. Optimization of $\mathbf{c 5}$, the five-residue macrocycle (Fig. 1b), with density functional theory (DFT) calculations revealed a slightly puckered conformation (Fig. S1a). In contrast, the analogous six-residue macrocycle has a significantly crinkled shape, indicating a strained structure (Fig. S1b). The cyclic backbone of $\mathbf{c 5}$, along with the intramolecular hydrogen bonds, hinders the rotation of the aryl-amide single bonds, which greatly reduces the conformational flexibility of the backbone. The intramolecular hydrogen bonds also prevent the amide groups from flipping $180^{\circ}$, forcing the amide $\mathrm{NH}$ and phenyl $\mathrm{CH}$ groups to point to the center of the macrocycle (Figs. 1b,c and S1a). The formation of $\mathbf{c 5}$ is calculated to be 5.93

$121 \mathrm{kcal} / \mathrm{mol}$ endothermic with respect to its acyclic counterpart (Fig. S2), which is a result of the repulsion 
close proximity by the cyclized backbone. As confirmation, an energy decomposition analysis (EDA) reveals $\mathbf{c 5}$ as being $16.91 \mathrm{kcal} / \mathrm{mol}$ less stable, but the system does gain stability through greater orbital interaction $(-9.57 \mathrm{kcal} / \mathrm{mol})$ when compared to the linear pentamer. Consequently, macrocycle $\mathbf{c 5}$, with its highly electropositive cavity, as shown with DFT computed Hirshfeld charges of $+0.121 e$ and $+0.037 e$ for $\mathrm{NH}$ and $\mathrm{CH}$ protons, respectively, is in a high-energy unbound state ${ }^{41}$ that is predisposed for binding anions.

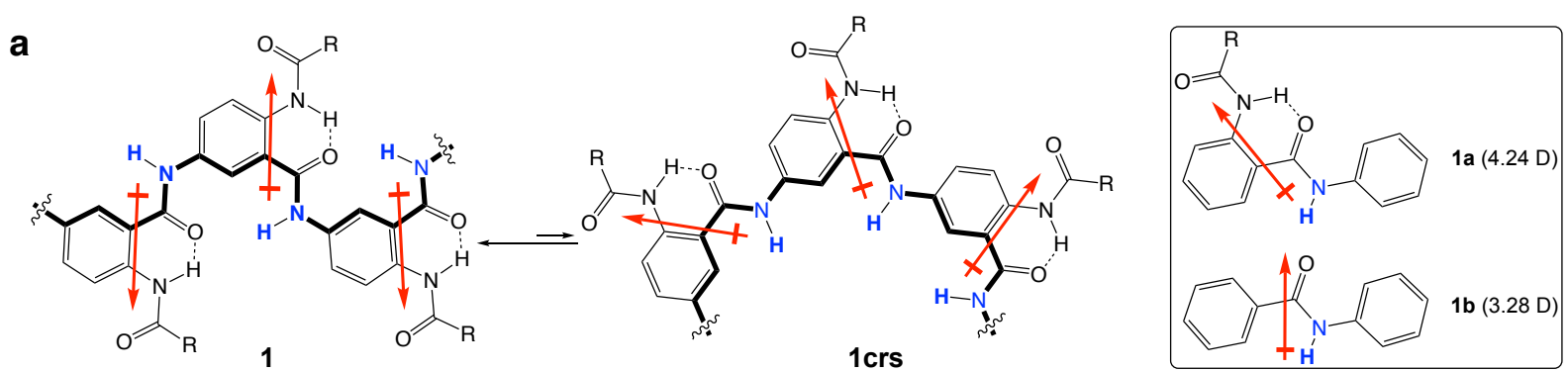

b<smiles>[R]c1nc2ccc(N)cc2c(=O)o1</smiles>

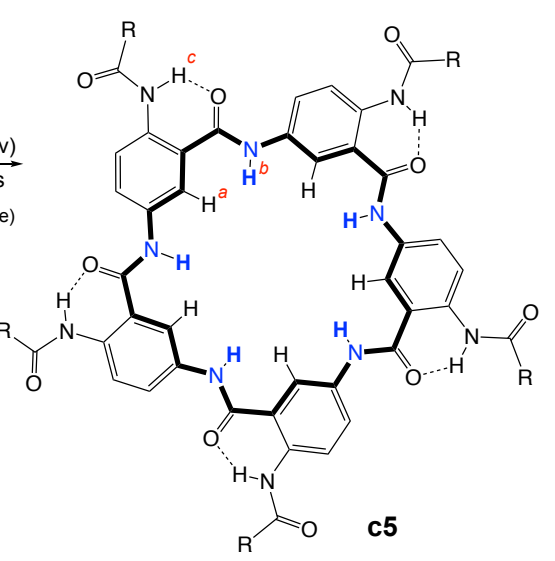

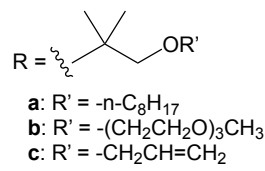

a: $\mathrm{R}^{\prime}=-\mathrm{n}-\mathrm{C}_{8} \mathrm{H}_{17}$
b: $\mathrm{R}^{\prime}=-\left(\mathrm{CH}_{2} \mathrm{CH}_{2} \mathrm{O}\right)_{3} \mathrm{CH}_{3}$
c: $\mathrm{R}^{\prime}=-\mathrm{CH}_{2} \mathrm{CH}=\mathrm{CH}_{2}$

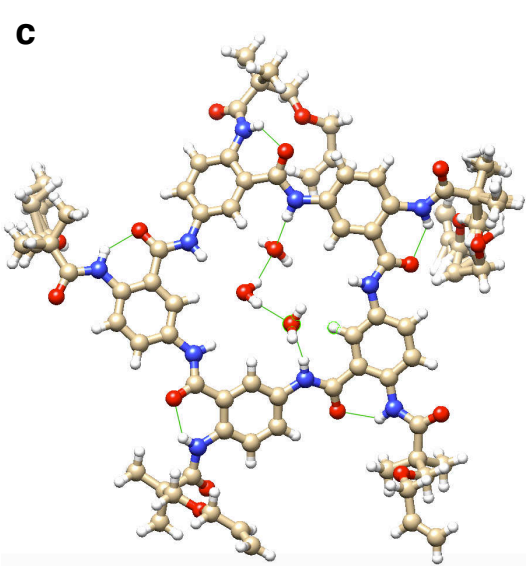

Figure 1 | Linear oligoamide 1 and macrocycles c5 consisting of basic residues derived from 5amino-N-acylanthranilic acid. a, Linear oligoamides 1 with its energetically unfavorable crescent conformation $1 \mathrm{crs}$, and the overall electrical dipole moments of amides $1 \mathrm{a}$ and $\mathbf{1 b}$ in the depicted conformations from DFT calculations performed with the $\mathrm{ADF}^{34}$ software package. $\mathbf{b}$, Synthesis of macrocycles $\mathbf{c 5 a - c}$ based on a one-pot macrocyclization process. In $\mathbf{a}$ and $\mathbf{b}$, the backbones of the linear and cyclic oligoamides are highlighted with thick bonds. c. Crystal structure of macrocycle c5c in which two of the five side chains are disordered with water molecules being hydrogen-bonded to the backbone $\mathrm{NH}$ groups.

One-pot synthesis of macrocycles c5. The designed pentaamides $\mathbf{c 5}$ are a series of new shape-persistent macrocycles that cannot be synthesized based on established amide-coupling chemistry ${ }^{35}$. To synthesize c5a, a stepwise approach was first attempted. Using the amide-coupling strategy we developed recently ${ }^{35}$, the linear precursor of $\mathbf{c 5 a}$, prepared by starting from monomer 2a in multiple steps, was cyclized to give c5a in an overall yield of $22 \%$ (Scheme S1 and Supplementary Information). Subsequently, we were able to develop a much more efficient, one-pot synthesis of $\mathbf{c 5 a}$ by probing the conditions for the ring-opening reaction of the benzoxazinone monomer 2a (Fig. 1b). In toluene, while heating $2 \mathbf{a}(2 \mathrm{mM})$ and $4-(N, N-$ dimethylamino)pyridine hydrochloride (DMAP• $\mathrm{HCl}$ ) and DMAP•HI under reflux led to $\mathbf{c 5 a}$ in $5 \%$ and $0 \%$ 
yields, respectively, treating 2a and DMAP• $\mathrm{HBr}(40 \mathrm{~mol} \%$ ) under the same condition gave c5a in $27 \%$ yield, indicating that $\mathrm{Br}^{-}$served as a template for one-pot cyclization. Replacing DMAP $\cdot \mathrm{HBr}$ with the 1:1 mixture of diphenyl phosphate (DPP) and DMAP (40 mol\%) significantly improved the yield ( 42\%) of c5a, suggesting that the DPP anion is a more effective template than Br- Based on the same one-pot procedure, macrocycles $\mathbf{c 5 b}$ and $\mathbf{c 5 c}$, which carry sidechains having tri(ethylene glycol) (Tg) and allyl tails, were synthesized from monomers $\mathbf{2} \mathbf{b}$ and $\mathbf{2} \mathbf{c}$ in yields of $38 \%$ and $39 \%$. The one-pot macrocyclization process has provided a simple and scalable route allowing further structural tuning and optimization, for instance, by adjusting the side chains and by screening additional anions as templates, based on which a variety of $\mathbf{c 5}$ derivatives can be obtained in sufficient quantities.

Crystal structure of $\mathbf{c 5 c}$ and solution properties of c5a-c. Single crystals of $\mathbf{c 5 c}$ were obtained from $\mathrm{CHCl}_{3}: \mathrm{CH}_{3} \mathrm{CN}(1: 1, \mathrm{v} / \mathrm{v})$ by slow evaporation of solvent. The crystal structure of $\mathbf{c 5 c}$ confirms our design (Fig. 1c). Macrocycle $\mathbf{c 5 c}$ has an overall planar conformation that resembles the energy-minimized structure of $\mathbf{c 5}$ (Fig. S1a). Consistent with our design, all the endocyclic $\mathrm{NH}$ and $\mathrm{CH}$ groups of $\mathbf{c 5 c}$ point to the center of the macrocycle (Fig. 1c) and defines a cavity of $\sim 6.8 \AA$ ( $\mathrm{H}$ to $\mathrm{H}$ ) or $\sim 4.6 \AA$ (van der Waals). Dihedral angles from $0^{\circ}$ to $40^{\circ}$ are observed between the backbone amide groups and their flanking benzene rings, leading to a slightly puckered conformation that presumably alleviates the repulsion between the amide dipoles and between the partially positive endocyclic hydrogens. The intramolecular hydrogen bonds also enforce the coplanar alignment of the side chain amide groups and the benzene rings to which they are attached. In addition, three water molecules are hydrogen-bonded to amide protons $b$ in the cavity.

Examining the packing of $\mathbf{c 5 c}$ in the solid state indicates that any two adjacent macrocycles have only a small portion, about one residue, of their backbones being stacked at $\sim 3.4 \AA$ (Fig. S3). The small contact surface between the neighboring molecules of $\mathbf{c 5 c}$ is likely caused by the need to avoid the repulsive interactions between the amide dipoles that would arise should the macrocycles stack face-to-face.

The lack of strong stacking interactions between the macrocyclic molecules is reflected by the overall good solubility of macrocycles c5a-c in solvents such as chloroform, which contrasts with the poor solubilities typical of most acyclic and cyclic aromatic oligoamides. In fact, macrocycle c5a is readily soluble in $\mathrm{CHCl}_{3}, \mathrm{CH}_{2} \mathrm{Cl}_{2}$, DMF, and DMSO. With its polar side chains having the Tg tails, macrocycle $\mathbf{c 5 b}$ is not only soluble in many organic solvents, but also in water with a reasonable solubility $(\sim 1 \mathrm{mM})$.

The ${ }^{1} \mathrm{H}$ NMR spectra of macrocycles c5a-c in $\mathrm{CDCl}_{3}(0.2 \mathrm{mM})$ reveal dispersed resonances (Fig. S4), lending further support for the limited self-aggregation of these macrocycles as indicated by the crystal structure of c5c. In DMSO- $d_{6}: \mathrm{CDCl}_{3}$ with $1 \%$ to $100 \%(\mathrm{v} / \mathrm{v}) \mathrm{DMSO}-d_{6}$, the NMR signals of $\mathbf{c 5 a}(1 \mathrm{mM})$ remain sharp, with the resonance of sidechain amide protons $c$ showing an upfield shift of $-0.5 \mathrm{ppm}$, backbone amide protons $b$ exhibiting a large downfield shift of $1.41 \mathrm{ppm}$, and that of the endocyclic $\mathrm{CH}$ proton $a$ experiencing a very small downfield shift of $0.06 \mathrm{ppm}$ (Fig. S5). These observations demonstrate that amide protons $b$ are exposed to solvent and engage in hydrogen-bonding interactions with DMSO

186 High-affinity anion recognition by macrocycles c5. We anticipate that macrocycles c5, with all the binding sites being highly preorganized, will serve as new anion receptors with hitherto unknown, versatile binding capability. The non-deformable cavity of $\mathbf{c 5}$ may result in size-dependent anion binding. With the endocyclic $\mathrm{NH}$ and $\mathrm{CH}$ groups providing two different types of hydrogen-bond donors, macrocycles $\mathbf{c 5}$ 
190

191

192

193

may accommodate anions of markedly different properties. The size of the anion, the properties of the solvents, and the hydrogen-bonding capability of both the anions and solvents, are all important factors affecting anion binding.
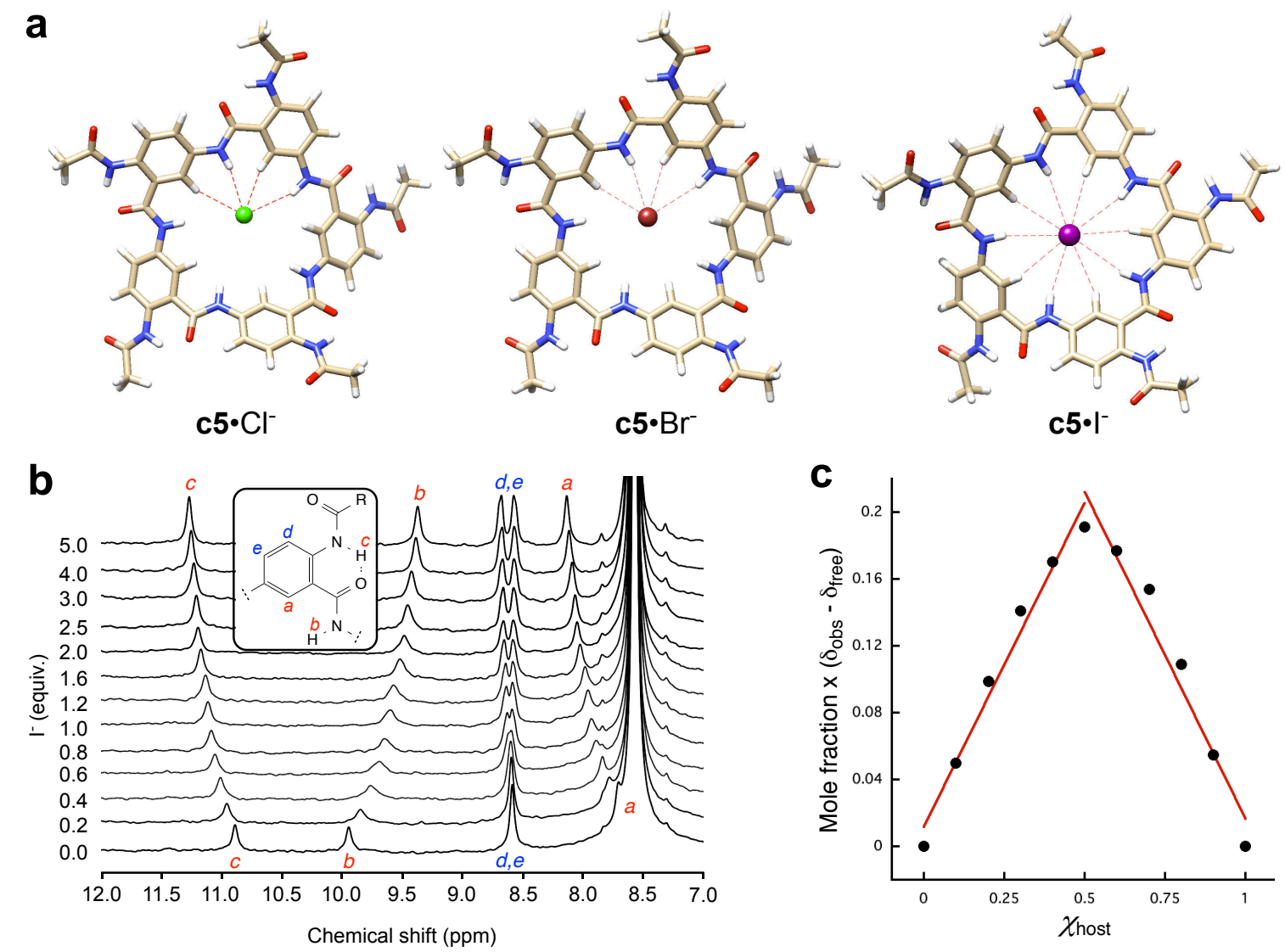

d
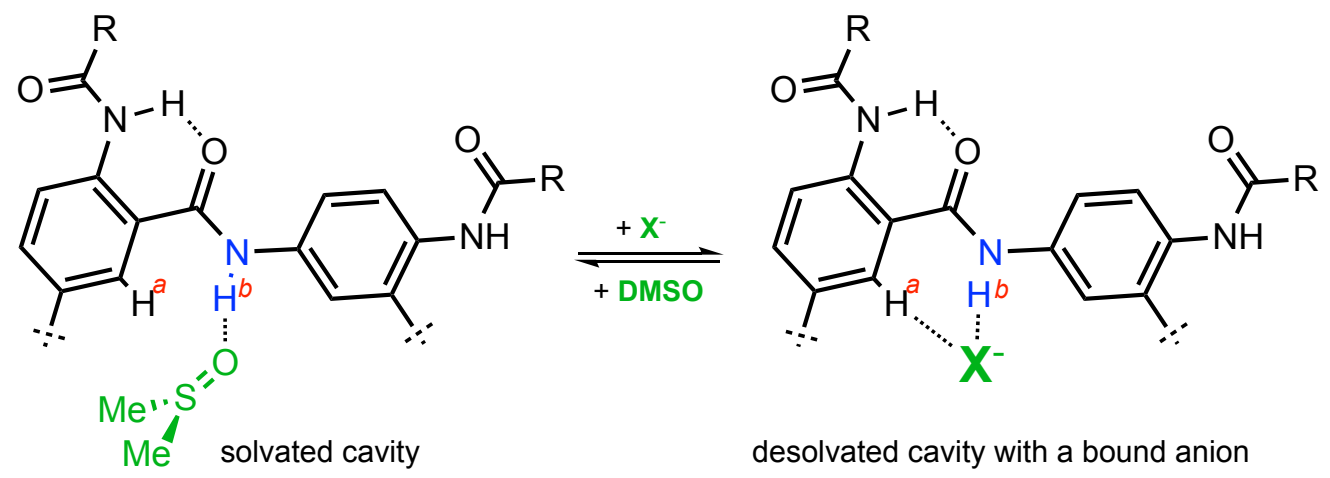

Figure 2 | Complexes of macrocycle c5 with halide ions. a, Optimized structures of the complexes of c5 with chloride, bromide, and iodide. In each complex, the $\mathrm{CH} / \mathrm{NH}$ protons and the halide ion that are within van der Waals contact distances $\left(d_{\mathrm{H} \ldots \mathrm{Cl}^{-}}<3.0 \AA ; d_{\mathrm{H} \ldots \mathrm{Br}}<3.1 \AA ; d_{\mathrm{H} \ldots \mathrm{I}}-<3.3 \AA\right)$ are indicated by red dashed lines. $\mathbf{b},{ }^{1} \mathrm{H}$ NMR spectra of $\mathbf{c} 5 \mathbf{a}(0.1 \mathrm{mM})$ titrated with 0 to 5 equiv. of TBA $\bullet$ in DMSO- $d_{6}: \mathrm{CDCl}_{3}$ $(15: 85, \mathrm{v} / \mathrm{v})$. c), Job plot of $\mathbf{c 5 a}$ with TBA $\bullet$ in DMSO- $d_{6}: \mathrm{CDCl}_{3}(15: 85, \mathrm{v} / \mathrm{v})$. d, The solvated cavity of $\mathbf{c 5}$ with DMSO molecule(s) hydrogen-bonded to amide protons $b$ (left) and the desolvated cavity of c5 occupied by an anion $\left(\mathbf{X}^{-}\right)$which forms hydrogen bonds with amide protons $b$ and phenyl protons a (right). 
(i) Binding of halides and perchlorate. Differing in their diameters $\left(\mathrm{Cl}^{-}: d=3.4 \AA\right.$; $\mathrm{Br}^{-}: d=3.8 \AA, \mathrm{I}^{-}: d$ $=4.2 \AA)$ and hydrogen-bonding capability $\left(\mathrm{Cl}^{-}>\mathrm{Br}^{-}>\mathrm{I}^{-}\right)$, the spherical halides provide comparable substrates for examining the interaction between $\mathbf{c 5}$ and anions. Fig. 2a shows the computationally optimized 1:1 complex of $\mathbf{c 5}$ with the halides. $\mathrm{I}^{-}$locates at the center of the macrocycle and is within van der Waals contact distances with all endocyclic $\mathrm{CH}$ and $\mathrm{NH}$ hydrogens. In contrast, $\mathrm{Cl}^{-}$or $\mathrm{Br}^{-}$occupies only part of the cavity that are within the van der Waals contact distances with two $\mathrm{CH}$ protons and two $\mathrm{NH}$ protons, respectively.

In DMSO- $d_{6}: \mathrm{CDCl}_{3}(15: 85, \mathrm{v} / \mathrm{v}, \varepsilon=11)$, in which $\mathbf{c 5 a}$ undergoes no self-aggregation as indicated by the lack of concentration-dependent shift of the ${ }^{1} \mathrm{H}$ resonances (Fig. S6), titrating c5a $(0.1 \mathrm{mM})$ with tetrabutylammonium (TBA) halides ( 0 to 5 equiv.) caused phenyl protons $a$ to downfield shift by $0.20 \mathrm{ppm}$ with $\mathrm{Cl}^{-}, 0.13 \mathrm{ppm}$ with $\mathrm{Br}^{-}$, or $0.43 \mathrm{ppm}$ with $\mathrm{I}^{-}$(Figs. $2 \mathrm{~b}$ and $\mathrm{S} 7 \mathrm{a}, \mathrm{b}$ ). Given that protons $a$ have almost no interaction with DMSO (Fig. S5), the halide-induced changes in chemical shift reflect the strengths of the $\mathrm{C}-\mathrm{H} \cdot \cdots$ halide hydrogen bonds, with the interaction of $\mathrm{I}^{-}$with protons $a$ being the strongest. The shifts of protons $a$ also show that the halides are bound in the cavity of $\mathbf{c 5 a}$.

Compared to protons $a$, the signal of amide protons $b$ shifts very differently under the same conditions (Figs. 2a and S7). $\mathrm{Cl}^{-}$induces a small (0.08 ppm) downfield shift, while $\mathrm{Br}^{-}$causes a very small (-0.02 ppm) and $\mathrm{I}^{-}$a much larger $(-0.57 \mathrm{ppm})$ upfield shift. The seemingly irregular shifts of protons $b$ induced by different halides can be explained by the competition between DMSO and the halides for hydrogen bonding. As shown in Fig. 2d, binding a halide to c5a expels the DMSO molecules from the cavity. Binding $\mathrm{Cl}^{-}$leads to stronger hydrogen-bonding strength "felt" by protons $b$, causing the ${ }^{1} \mathrm{H}$ resonance to shift further downfield. On the other hand, displacing DMSO by $\mathrm{Br}^{-}$and especially $\mathrm{I}^{-}$, as weaker hydrogen-bond acceptors $^{42}$, results in reduced hydrogen-bonding strengths sensed by protons $b$, leading to upfield shifts.

The shifts of protons $b$ are consistent with the hydrogen-bond acceptor strengths of the three halides, i.e., $\mathrm{Cl}^{-}$and $\mathrm{I}^{-}$form the strongest and weakest hydrogen bonds, respectively, with protons $b$. In contrast, the downfield shifts of $\mathrm{CH}$ protons $a$, which clearly demonstrate that protons $a$ sense enhanced hydrogen bonding strengths upon binding the halides, are inconsistent with the hydrogen-bonding capability of the halides. It is surprising that $\mathrm{I}^{-}$, the weakest hydrogen-bond acceptor, causes the largest downfield shift of protons $a$ and thus interacts most strongly with protons $a$, which implies that, different from typical hydrogen-bond donors, the $\mathrm{CH}$ units of $\mathbf{c 5 a}$ favor large anions with diffused charge density.

The titration data in DMSO- $d_{6}: \mathrm{CDCl}_{3}(15: 85, \mathrm{v} / \mathrm{v})$ fit well into a $1: 1$ binding model using the online fitting tool Bindfit ${ }^{36}$, giving association constants $(K)$ of $(4.5 \pm 0.2) \times 10^{3} \mathrm{M}^{-1},(8.4 \pm 0.7) \times 10^{3} \mathrm{M}^{-1}$, and $(2.7 \pm 0.3) \times 10^{4} \mathrm{M}^{-1}$ for $\mathrm{Cl}^{-}, \mathrm{Br}^{-}$, and $\mathrm{I}^{-}$, respectively. The $1: 1$ binding of $\mathbf{c 5 a}$ with each halide is confirmed by a Job's plot (Figs. 2c and S8). The $K$ values show that c5a binds the largest halide, $\mathrm{I}^{-}$, with the highest affinity. The preference of c5a for large, weakly hydrogen-bonding anions is further demonstrated with perchlorate $\left(\mathrm{ClO}_{4}^{-}\right)$, a tetrahedral oxoanion having a slightly larger size $(d=4.5 \AA)$ but being a weaker hydrogen-bond acceptor than I-. Titrating c5a $(0.1 \mathrm{mM})$ with $\mathrm{TBA}^{-} \mathrm{ClO}_{4}\left(0-5\right.$ equiv.) in DMSO- $d_{6}: \mathrm{CDCl}_{3}$ (15:85) induced a downfield shift $(0.107 \mathrm{ppm})$ for phenyl protons $a$, but a large $(-0.803 \mathrm{ppm})$ upfield shift for amide protons $b$ (Fig. S7c), based on which a $K$ of $(6.3 \pm 0.8) \times 10^{4}$ for $\mathrm{ClO}_{4}{ }^{-}$was obtained. The shifts of protons $a$ and $b$ are consistent with $\mathrm{ClO}_{4}{ }^{-}$being a weaker hydrogen acceptor than $\mathrm{I}^{-}$. The larger $\mathrm{K}$ of $\mathrm{ClO}_{4}{ }^{-}$ than that of $\mathrm{I}^{-}$probably reflects the slightly larger size of the former, which matches the cavity of c5a better. selectivity ratios increase to 14,7 , and 2 folds over $\mathrm{Cl}^{-}, \mathrm{Br}^{-}$, and $\mathrm{I}^{-}$, respectively. 
Ion binding has been believed to be electrostatically driven, on which solvent polarity, as roughly reflected by dielectric constants $(\varepsilon)$, exerts a major impact. Halide binding by c5a was quantified by isothermal titration calorimetry (ITC) in DMSO: $\mathrm{CHCl}_{3}(5: 95, \mathrm{v} / \mathrm{v}, \varepsilon=6.9)$ and $\mathrm{MeOH}: \mathrm{CHCl}_{3}(5: 95, \mathrm{v} / \mathrm{v}, \varepsilon$ = 6.2), two mixed solvents with similar polarity. In DMSO: $\mathrm{CHCl}_{3}(5: 95)$, the $K$ 's are from $10^{4}$ to $10^{5} \mathrm{M}^{-1}$ (Fig. S9 and Table S1), 10 times of those in DMSO- $d_{6}: \mathrm{CDCl}_{3}(15: 85, \varepsilon=11)$, which demonstrates that lowering solvent polarity increases the affinity of $\mathbf{c 5 a}$ for halides. In $\mathrm{MeOH}: \mathrm{CHCl}_{3}(5: 95)$, the $K$ 's are around $10^{6} \mathrm{M}^{-1}$ (Fig. S10 and Table S1), 100 times of those in DMSO- $d_{6}: \mathrm{CDCl}_{3}(15: 85)$. Given the similar polarities of the two mixed solvents, the markedly enhanced affinity of $\mathbf{c 5 a}$ for halides in $\mathrm{MeOH}: \mathrm{CHCl}_{3}$ (5:95) was unexpected.

To gain further insights, compound $\mathbf{c 5 a}(0.1 \mathrm{mM})$ was subjected to ${ }^{1} \mathrm{H}$ NMR titration with TBA $\bullet$ halide (0-5 equiv.) in $\mathrm{CD}_{3} \mathrm{CN}: \mathrm{CDCl}_{3}(80: 20, \mathrm{v} / \mathrm{v}, \varepsilon=31)$, a mixed solvent that is much more polar than DMSO$d_{6}: \mathrm{CDCl}_{3}(15: 85, \mathrm{v} / \mathrm{v}, \varepsilon=11)$. Downfield shifts of amide protons $b$ and phenyl protons $a$ are induced by all three halides (Fig. S12), indicating that both protons $a$ and $b$ experience enhanced hydrogen-bonding strength upon binding halides. The titration data fit into a 1:1 binding model, giving $K$ values of $(9.7 \pm 1.1)$ $\times 10^{4} \mathrm{M}^{-1}$ (for $\left.\mathrm{Cl}^{-}\right),(5.0 \pm 0.5) \times 10^{4} \mathrm{M}^{-1}$ (for $\left.\mathrm{Br}^{-}\right)$, and $(6.0 \pm 0.9) \times 10^{5} \mathrm{M}^{-1}$ (for $\mathrm{I}^{-}$), which are 10 to 20 times of the $K$ 's in DMSO- $d_{6}: \mathrm{CDCl}_{3}(15: 85)$. In $\mathrm{CD}_{3} \mathrm{CN}: \mathrm{CDCl}_{3}(5: 95, \mathrm{v} / \mathrm{v}, \varepsilon=6.4)$, the binding affinities $\left(K_{\mathrm{a}}\right.$ 's) of $\mathbf{c 5 a}$ for the halides revealed by ITC reach $10^{6} \mathrm{M}^{-1}$ for $\mathrm{Cl}^{-}$, and $10^{7} \mathrm{M}^{-1}$ for $\mathrm{Br}^{-}$and $\mathrm{I}^{-}$(Table S1 and Figure S11). The enhanced affinities of $\mathbf{c 5 a}$ for the halides can be rationalized by the fact that, compared to DMSO, acetonitrile is a much weaker hydrogen-bond acceptor ${ }^{43}$ and can be replaced from the cavity of $\mathbf{c 5}$ at reduced energy costs. These results demonstrate that the hydrogen-bonding capabilities of solvents play a dominant role in determining the binding affinity of $\mathbf{c 5}$ for the halides.

(ii) High-affinity binding of strongly hydrogen-bonding oxoanions. The high affinities of c5a for $\mathrm{I}^{-}$and $\mathrm{ClO}_{4}{ }^{-}$indicate that weakly hydrogen-bonding anions with sizes matching the cavity of $\mathbf{c 5}$ can achieve strong binding. We thus expect that anions with both suitable (matching) sizes and strong hydrogen-bonding ability can have drastically enhanced interaction with $\mathbf{c} 5$ by maximizing their interaction with $\mathrm{NH}$ protons $b$ and $\mathrm{CH}$ protons $a$.

Acetate $\left(\mathrm{AcO}^{-}\right)$, diphenyl phosphate (DPP), and monomethyl phenylphosphonate (MPP) (Figure 3a), oxoanions that are very strong hydrogen-bond acceptors ${ }^{43}$, were examined for their binding with c5a and c5b. In DMSO- $d_{6}: \mathrm{CDCl}_{3}(15: 85, \mathrm{v} / \mathrm{v})$, upon adding less than one equiv. of the TBA salt of $\mathrm{AcO}^{-}$or MPP, or the tetramethylammonium (TMA) salt of DPP, macrocycle c5a gave two sets of peaks for protons $a, b$, or $c$ in the ${ }^{1} \mathrm{H}$ NMR spectrum (Figs. 3b and S7d,e), indicating a slow exchange between the free and bound forms of $\mathbf{c 5 a}$ on the NMR time scale. Binding affinities were determined with two-step competition ${ }^{1} \mathrm{H}$ NMR titration experiments by using $\mathrm{Cl}^{-}$as the competitor (Supplementary Information and Fig. S13). Macrocycle c5a was found to tightly bind the three oxoanions in a 1:1 ratio. The larger DPP and MPP $(d \approx$ $4.3 \AA$ ) show stronger binding with $K$ values of $(1.6 \pm 0.1) \times 10^{6} \mathrm{M}^{-1}$ and $(1.1 \pm 0.1) \times 10^{7} \mathrm{M}^{-1}$, respectively, than that $\left((2.4 \pm 0.3) \times 10^{5} \mathrm{M}^{-1}\right)$ of the smaller $\mathrm{AcO}^{-}(d=3.8 \AA)$, based on which selectivity ratios of 53, 356, and 2,444 for AcO- DPP, and MPP, respectively, over $\mathrm{Cl}^{-}\left(K=(4.5 \pm 0.2) \times 10^{3} \mathrm{M}^{-1}\right)$ are found.

In $\mathrm{CD}_{3} \mathrm{CN}: \mathrm{CDCl}_{3}(40: 60, \mathrm{v} / \mathrm{v}, \varepsilon=18)$, competition ${ }^{1} \mathrm{H}$ NMR titrations with $\mathrm{Cl}^{-}\left(K=(9.7 \pm 1.0) \times 10^{4} \mathrm{M}^{-}\right.$ respectively (Fig. S14), which give selectivity ratios of 310 and 3,200 for DPP and MPP, respectively, over $\mathrm{Cl}^{-}$. The interaction of c5a with the oxoanions, especially with the larger DPP and MPP, demonstrate that anions combining size-matching and strongly hydrogen-bonding capabilities, by involving the maximum 
number of $\mathrm{NH}$ and $\mathrm{CH}$ donors and effectively outcompeting solvent molecules for hydrogen-bonding, can achieve remarkable binding affinity and selectivity.

289
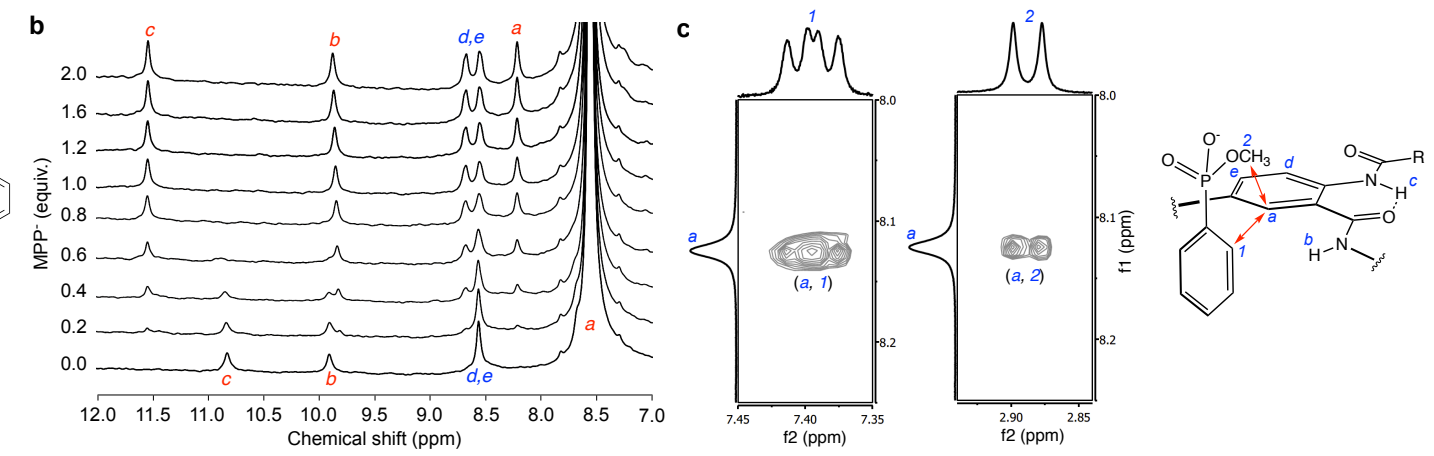

f2 (ppm) a<smiles>CC(=O)O</smiles>

$\mathrm{AcO}$

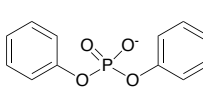

DPP

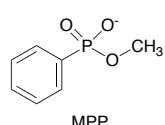

MPP

Figure $3 \mid{ }^{1} \mathbf{H}$ NMR spectra of $\mathbf{c 5 a}$. a, Structures of three strongly hydrogen-bonding oxoanions. $\mathbf{b}$, Spectra of c5a $(0.1 \mathrm{mM})$ titrated with 0 to 2 equiv. of TBA.MPP, in 15:85 (v/v) DMSO- $d_{6}: \mathrm{CDCl}_{3}$ at $25^{\circ} \mathrm{C}$. c, Partial 2D (ROESY) spectra of the $1: 1$ mixture of c5a and TBA・MPP in DMSO-d6 $(20 \mathrm{mM}, 500 \mathrm{MHz}$, mixing time $=0.4 \mathrm{~s}, 25^{\circ} \mathrm{C}$ ).

The superb anion binding ability of macrocycles $\mathbf{c 5}$ was also demonstrated in highly competitive solvents. Based on ${ }^{1} \mathrm{H}$ NMR titrations, in DMSO- $d_{6}: \mathrm{CDCl}_{3}(70: 30, \mathrm{v} / \mathrm{v}, \varepsilon=34), K$ values of $(2.4 \pm 0.1) \times$ $10^{3} \mathrm{M}^{-1}$ for DPP and $(4.7 \pm 0.6) \times 10^{4} \mathrm{M}^{-1}$ for MPP were obtained (Fig. S15). In the aqueous solvent mixture $\mathrm{D}_{2} \mathrm{O}$ :acetone- $d_{6}(20: 80, \mathrm{v} / \mathrm{v}, \varepsilon=33)$, macrocycle c5a showed strong affinities for DPP $(K=(3.8 \pm 0.4) \times$ $\left.10^{4} \mathrm{M}^{-1}\right)$ and $\operatorname{MPP}\left(K=(1.7 \pm 0.1) \times 10^{4} \mathrm{M}^{-1}\right)\left(\right.$ Fig. S16). Even in $\mathrm{D}_{2} \mathrm{O}$ :acetone- $d_{6}(60: 40, \mathrm{v} / \mathrm{v}, \varepsilon=56), \mathbf{c 5 b}$ was able to bind DPP with a $K$ of $(5.4 \pm 0.4) \times 10^{3} \mathrm{M}^{-1}$ (Fig. S17).

Two-dimensional (ROESY) NMR in DMSO- $d_{6}$ was performed on the 1:1 mixture of c5a and MPP to confirm the formation of complex c5a・MPP. ROEs between protons $a$ of $\mathbf{c 5 a}$ and protons 1 and 2 of MPP were clearly detected (Fig. 3c), suggesting that MPP indeed is located inside the cavity of c5a. In contrast, no significant ROE could be found between the protons 1 and 2 of MPP and exterior protons $d$ and $e$ of c5a.

Selective transmembrane transport of halide ions. The low propensity of macrocycle c5a for selfaggregation, along with its good solubility in organic solvents, suggests that the molecules of c5a are unlikely to stack into channels when partitioned into the lipid bilayer. However, given its anion-binding capability, especially in low-polar solvents, macrocycle c5a may facilitate anion transport across the lipid bilayer by acting as a carrier. We thus performed vesicle-based fluorescence assays (Fig. 4a) to determine the transport rates of the halides, which allowed the transport selectivity to be compared. Macrocycle c5a mediated transmembrane transport of $\mathrm{Cl}^{-}, \mathrm{Br}^{-}$, and $\mathrm{I}^{-}$, with the largest enhancement in $\mathrm{Cl}^{-}$transport (Fig. 4b), followed by $\mathrm{Br}^{-}$transport (Fig. 4c), and the smallest increase in $\mathrm{I}^{-}$transport, being observed (Fig. 4d). The total anion permeabilities (Fig. 4) of the halides mediated by c5a reveal that the transport of $\mathrm{Cl}^{-}, \mathrm{Br}^{-}$, and $\mathrm{I}^{-}$ follows a selectivity order of 35.6:2.8:1, which is inversely related to the binding affinities of $\mathbf{c 5 a}$ for these three halides. The selective transport of $\mathrm{Cl}^{-}$across the cell membrane is biologically and medically significant ${ }^{45}$. Natural chloride channels are known to be responsible for a broad range of functions ${ }^{46}$, with a large spectrum of diseases being caused by defective $\mathrm{Cl}^{-}$channels ${ }^{47}$. In this regard, macrocycle c5a provides an opportunity to develop synthetically tunable $\mathrm{Cl}^{-}$transporters to rectify ill functioned chloride 
channels in order to reestablish transmembrane chloride conductance. One important application is the treatment for cystic fibrosis where $\mathrm{Cl}^{-}$flux across epithelial cell membranes needs to be restored.
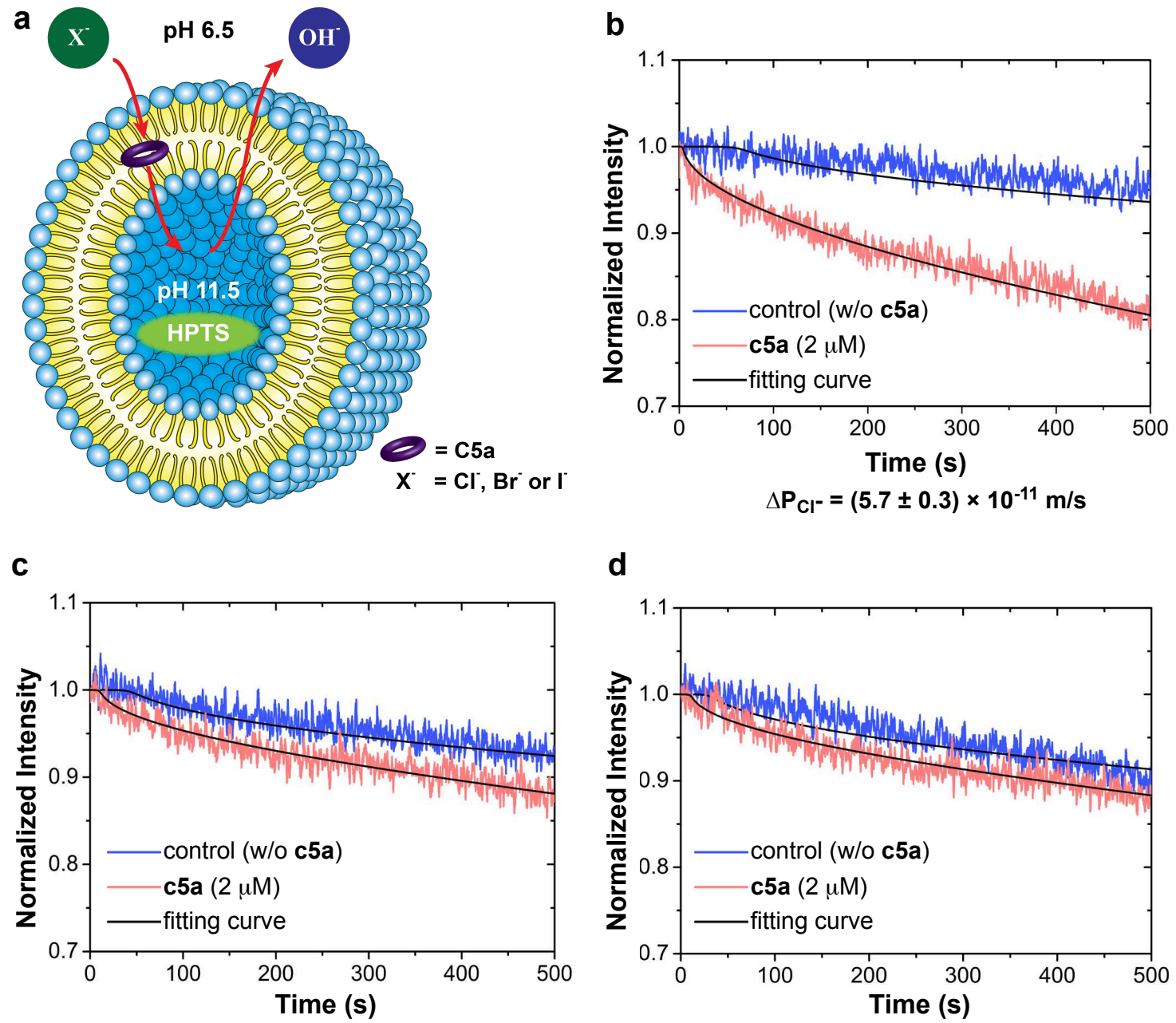

d

$\Delta \mathrm{P}_{\mathrm{Br}^{-}}=(4.5 \pm 0.5) \times 10^{-12} \mathrm{~m} / \mathrm{s}$

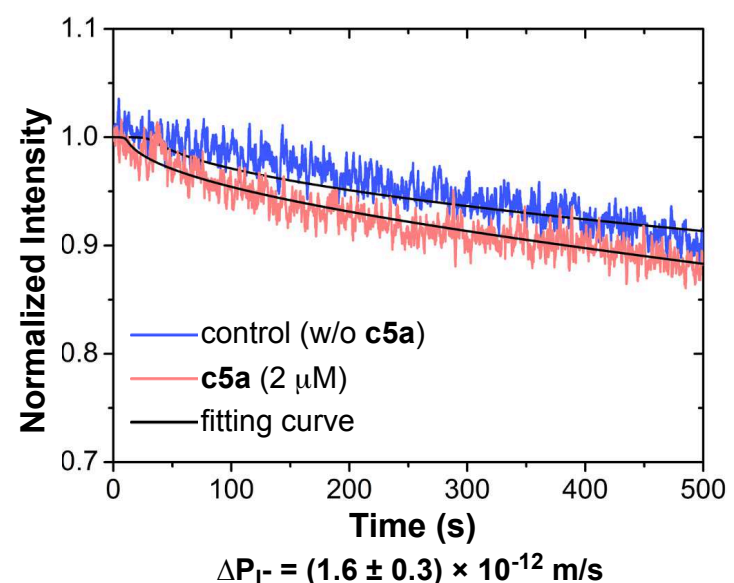

Figure 4 | Transmembrane transport of halide ions promoted by macrocycle c5a. a, Dissipation of the $\mathrm{pH}$ gradient, due to $\mathrm{OH}^{-} / \mathrm{Cl}^{-}$antiport or the functionally equivalent $\mathrm{H}^{+} / \mathrm{Cl}^{-}$symport, quenches emission of the $\mathrm{pH}$-sensitive dye HPTS entrapped in liposome. b, c, d, Normalized time-lapse fluorescence emission curves of $\mathrm{Cl}^{-}, \mathrm{Br}^{-}$, and $\mathrm{I}^{-}$transport facilitated by c5a, along with the control curves (in blue) measured with vesicles in the absence of c5a. The total anion permeability $\left(\Delta \mathrm{P} x^{-}\right)$of each halide ion elicited by c5a is shown.

Catalytic ester amidation. With their tetrahedral shapes and negative charges, many phosphate-related anions similar to DPP or MPP have served as analogs of the negatively charged, tetrahedral transition states of nucleophilic acyl substitution (NAS) reactions ${ }^{49,50}$. The high affinities of macrocycles $\mathbf{c 5 a}$ and $\mathbf{c 5 b}$ for DPP and MPP suggest that these macrocycles may be able to catalyze NAS reactions by binding and stabilizing the corresponding transition states. This intriguing possibility prompted us to probe the 
amidation of methyl esters 3a-c with $n$-octylamine, which gives amides $\mathbf{4 a - c}$, by using c5a as a likely catalyst (Fig. 5).

a

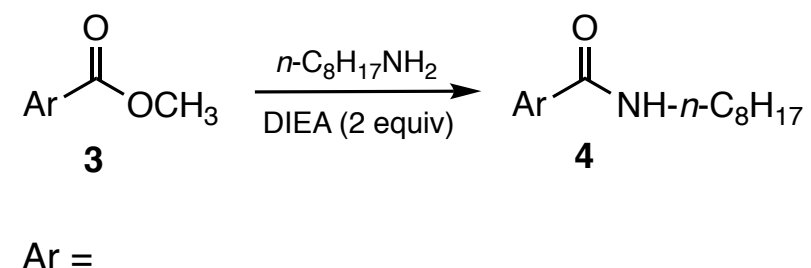

a:<smiles>O=[N+]([O-])c1cc(I)cc([N+](=O)[O-])c1</smiles><smiles>Fc1ccc(I)cc1</smiles><smiles>Ic1ccccc1</smiles>

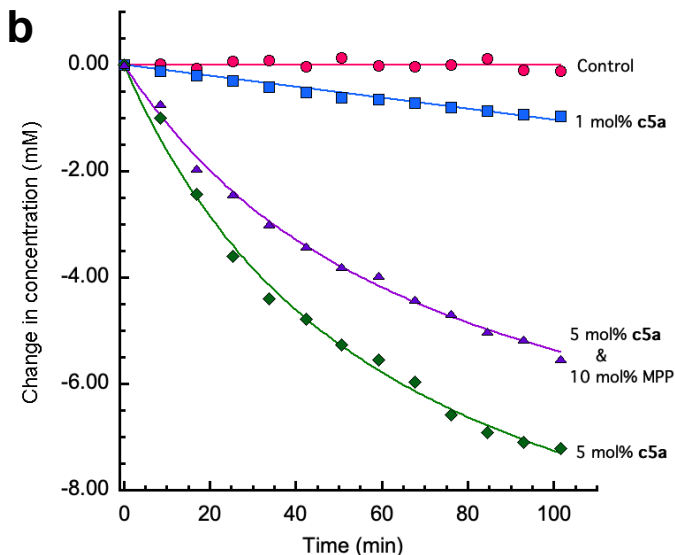

Figure 5 | The amidation of methyl esters $3 a-c$ with $\boldsymbol{n}$-octylamine. $\mathbf{a}$. The reactions were performed under neat reaction conditions with the molar ratio of ester:n-octylamine:DIEA of $1: 1.5: 2$, and $1 \mathrm{~mol} \%$ c5a at $60{ }^{\circ} \mathrm{C}$. The amidation of $\mathbf{3 a}$ was performed for $18 \mathrm{hrs}$, and those of $\mathbf{3 b}$ and $\mathbf{3 c}$ for $24 \mathrm{hrs}$. b. Timedependent change in the concentrations of ester $3 \mathbf{a}$ without c5a (control), with $1 \mathrm{~mol} \%$ c5a, $5 \mathrm{~mol} \%$ c5a, and $5 \mathrm{~mol} \%+10 \mathrm{~mol} \% \mathrm{MPP}$ monitored with ${ }^{1} \mathrm{H}$ NMR. The reactions were carried out with $0.5 \mathrm{M}$ of $3 \mathbf{a}$, $0.75 \mathrm{M}$ of $n$-octylamine, $1 \mathrm{M}$ of DIEA, and $50 \mathrm{mM}$ of $\mathrm{Cl}_{2} \mathrm{CHCHCl}_{2}$ (as the internal standard) in $\mathrm{CDCl}_{3}$ at 50 ${ }^{\circ} \mathrm{C}$.

As expected, the presence of c5a resulted in markedly increased conversion of esters 3a-c into amides 4a-c (Fig. 5). Esters 3a-c were first reacted with $n$-octylamine at $60{ }^{\circ} \mathrm{C}$ for 18 hours under neat reaction conditions. In the presence of $1 \mathrm{~mol} \% \mathbf{c 5 a}$, amides $\mathbf{4 a}, \mathbf{4 b}$, and $\mathbf{4} \mathbf{c}$ were isolated in yields of $97 \%, 78 \%$ and $85 \%$, respectively, which are significantly higher than the yields of $54 \%, 42 \%$, and $31 \%$ of amides $4 a-c$ formed under the same conditions without c5a (Fig. 5a).

The amidation of ester 3a was then monitored with ${ }^{1} \mathrm{H}$ NMR in $\mathrm{CDCl}_{3}$ (Fig. 5b). Over a period of $\sim 100$ minutes, the conversion of ester $\mathbf{3 a}$ was $\sim 0.9 \%$ in the absence of c5a. Adding $1 \mathrm{~mol} \%$ c5a results in increased conversion $(\sim 1.4 \%)$ of 3a. The presence of $5 \mathrm{~mol} \% \mathbf{c 5 a}$ further increased the conversion of $\mathbf{3 a}$ to $\sim 6.5 \%$. Including $10 \mathrm{~mol} \% \mathrm{MPP}$ and $5 \mathrm{~mol} \% \mathbf{c 5 a}$ in the reaction partially inhibited the conversion of $\mathbf{3 a}$ to $\sim 4.1 \%$, indicating that binding to the cavity of $\mathbf{c 5 a}$ was responsible for the observed catalysis. The formation of amide $4 \mathbf{a}$ was confirmed by NMR (Fig. S18). After $\sim 11 \mathrm{hrs,} \mathrm{more} \mathrm{than} 20 \%$ of 3a reacted in the presence of $5 \mathrm{~mol} \% \mathbf{c 5 a}$, while only $\sim 3 \%$ of $\mathbf{3 a}$ was converted in the absence of $\mathbf{c 5 a}$ (Fig. S19).

The catalytic amidation of ester 3a-c clearly demonstrates the capability of macrocycle c5a in promoting a NAS reaction by, most likely, binding and stabilizing the negative transition state of such a reaction. While the catalytic reactivity shown by c5a has validated our hypothesis, organocatalysts with improved and eventually optimized efficiencies should be available based on the ready structural tunability of macrocycles c5. 


\section{Conclusions}

372 Cyclic pentaamides c5a-c were synthesized from the one-pot macrocyclization of the corresponding monomers based on a novel amide coupling strategy we developed. These previously unknown shapepersistent macrocycles share a fully constrained backbone that rigidly locks endocyclic $\mathrm{NH}$ and $\mathrm{CH}$ groups into a convergent arrangement, leading to high-affinity binding of halides and oxoanions. Examining the binding affinities of $\mathbf{c 5}$ for halide ions reveal size-dependent recognition favoring iodide, while the complexation of oxoanions show that anions with both better matched sizes and strong hydrogen-bonding capability achieved remarkable binding affinities, even in highly polar solvents containing high proportions of water. The superb capability of macrocycles $\mathbf{c 5}$ to complex anions is demonstrated by the efficient and selective transport of chloride ions across lipid membranes and the intriguing catalytic amidation of esters brought about by c5a. The efficient, scalable one-pot synthetic procedure allows various derivatives of macrocycles $\mathbf{c} 5$ to be prepared in sufficient quantities with ready structural tunability. Based on this solid platform, the development of the next-generation anion binders, transporters, and organocatalysts can be envisioned.

\section{Methods}

Vesicle-based halide transport assays. The assays were based on adding unilamellar 1-palmitoyl-2oleoylphosphatidylcholine (POPC) vesicles having a defined $(100 \mathrm{~nm})$ diameter and loaded with HPTS $(30 \mu \mathrm{M})$ in a buffer (10 mM HEPES, $100 \mathrm{mM} \mathrm{NaX,pH} \mathrm{11.5)} \mathrm{to} \mathrm{a} \mathrm{buffered} \mathrm{solution} \mathrm{(100} \mathrm{mM} \mathrm{NaX,} 10 \mathrm{mM}$ HEPES at pH 6.5) containing c5a $(2 \mu \mathrm{M})$. The entrapped HPTS was excited at $450 \mathrm{~nm}($ slitex $=5 \mathrm{~nm})$ and the emission monitored at 510 $\mathrm{nm}\left(\right.$ slitem $\left._{\mathrm{f}}=5 \mathrm{~nm}\right)$. The measured emission intensities were normalized against those of the same vesicles which were lysed with $0.1 \%$ Triton X-100 at the end of each experiment. Each of the normalized time-lapse fluorescence emission curves was fitted with the quantitative model according to the Goldman-Hodgkin-Katz flux theory (orange lines) ${ }^{48}$, based on which the anion permeability of vesicles with or without $\mathbf{c 5 a}$ was determined. The total anion permeability $(\Delta \mathrm{Px}-)$ of each halide ion elicited by $\mathbf{c 5 a}$ was calculated by subtracting the anion permeability measured with vesicles in the absence of $\mathbf{c 5 a}$.

See the Supplementary Information for other information including synthetic steps, experimental conditions, analytical data, 1D and 2D NMR spectra, mass spectra, computational methods, and crystal structure.

\section{References}

1. National Research Council. Opportunities in Biology (1989). Washington, DC: The National Academic Press. 3 , Molecular Structure and Function. https://www.ncbi.nlm.nih.gov/books/NBK217812/

2. Whitty, A. Cooperativity and biological complexity. Nat. Chem. Biol. 4, 435-439 (2008).

404 3. Mahadevi, A. S. \& Sastry, G. N. Cooperativity in noncovalent interactions. Chem. Rev. 116, 2775-2825 (2016).

4. Zhou, Y., Morais-Cabral, J. H., Kaufman, A. \& MacKinnon, R. Chemistry of ion coordination and hydration revealed by a $\mathrm{K}^{+}$channel-Fab complex at $2.0 \AA$ resolution. Nature 414, 43-48 (2001).

5. Sui, H. X., Han, B. G., Lee, J. K., Walian, P., \& Jap, B. K. Structural basis of water-specific transport through the AQP1 water channel. Nature 414, 872-878 (2001).

6. Pflugrath, J. W., \& Quiocho, F. A. Sulphate sequestered in the sulphate-binding protein of Salmonella typhimurium is bound solely by hydrogen bonds. Nature 314, 257-260 (1985).

7. Wu, X., Gilchrist, A. M. \& Philip A. Gale, P. A. Prospects and challenges in anion recognition and transport. Chem 6, 1296-1309 (2020).

8. Molina, P., Zapata, F., \& Caballero, A. Anion recognition strategies based on combined noncovalent interactions. Chem. Rev. 117, 9907-9972 (2017). 
9. Sessler, J. L., Gale, P. A. \& Cho, W.-S. Anion Receptor Chemistry, RSC Publishing, Cambridge, U.K., 2006.

10. Massena, C. J., Wageling, N. B., Decato, D. A., Martin Rodriguez, E., Rose, A. M., \& Berryman, O. B. A halogen-bond-induced triple helicate encapsulates iodide. Angew. Chem., Int. Ed. 55, 12398-12402 (2016).

11. Borissov, A. et al. Anion recognition in water by charge-neutral halogen and chalcogen bonding foldamer receptors. J. Am. Chem. Soc. 141, 4119-4129 (2019).

12. Benz, S. et al. Anion transport with chalcogen bonds. J. Am. Chem. Soc. 138, 9093-9096 (2016).

13. Cabbines, D. K. \& Margerum, D. W. Macrocyclic effect on the stability of copper(II) tetramine complexes. $J$. Am. Chem. Soc. 91, 6540-6541 (1969).

14. Rebek, Jr. J. Model studies in molecular recognition. Science 235, 1478-1484 (1987).

15. Rebek Jr., J., Askew, B., Killoran, M., Nemeth, D., \& Lin, F. T. Convergent functional groups. 3. A molecular cleft recognizes substrates of complementary size, shape, and functionality. J. Am. Chem. Soc. 109, 2426-2431 (1987).

16. Gong, B. et al. Creating nanocavities of tunable sizes: Hollow Helices. Proc. Natl. Acad. Sci. U. S. A. 99, 1158311588 (2002).

17. Jiang, H., Léger, J. M. \& Huc, I. Aromatic $\delta$-peptides. J. Am. Chem. Soc.125, 3448-3449 (2003).

18.Zhang, D. W., Zhao, X., Hou, J. L. \& Li, Z.T. Aromatic amide foldamers: Structures, properties, and functions. Chem. Rev. 112, 5271-5316 (2012).

19. Dobscha, J. R., Liu, Y. \& Flood, A. H., Shape-persistent anion receptors. In Comprehensive Supramolecular Chemistry II; Elsevier, 2016

20. Yuan, L. H. et al. Highly efficient, one-step macrocyclizations assisted by the folding and preorganization of precursor oligomers. J. Am. Chem. Soc. 126, 11120-11121 (2004).

21. Höger, S. Shape-persistent macrocycles: From molecules to materials. Chem. Eur. J. 10, 1320-1329 (2004).

22. Qin, B. et al. Crystallographic evidence of an unusual, pentagon-shaped folding pattern in a circular aromatic pentamer. Org. Lett. 10, 5127-5130 (2008).

23. Guieu, S., Crane, A. K. \& MacLachlan, M. J. Campestarenes: novel shape-persistent Schiff base macrocycles. Chem. Commun. 47, 1169-1171 (2011).

24.Zhang, J., Pesak, D. J., Ludwick, J. L. \& Moore, J. S. Geometrically-controlled and site-specificallyfunctionalized phenylacetylene macrocycles. J. Am. Chem. Soc. 116, 4227-4239 (1994).

25. Seidel, D., Lynch, V. \& Sessler, J. L. Cyclo[8]pyrrole: A simple-to-make expanded porphyrin with no meso bridges. Angew. Chem. Int. Ed. 41, 1422-1425 (2002).

26. Lee, S. M., Chen, C. H. \& Flood, A. H. A pentagonal cyanostar macrocycle with cyanostilbene CH donors binds anions and forms dialkylphosphate [3]rotaxanes. Nat. Chem. 5, 704-710 (2013).

27. Li, Y. \& Flood, A. H. Pure C-H hydrogen bonding to chloride ions: a preorganized and rigid macrocyclic receptor. Angew. Chem. Int. Ed. 47, 2649-2652 (2008).

28. Bisson, A. P., Lynch, V.M., Monahan, M.-K.C. \& Anslyn, E. V. Recognition of anions through NH- $\pi$ hydrogen bonds in a bicyclic cyclophane - Selectivity for nitrate. Angew. Chem. Int. Ed. Engl. 36 2340-2342 (1997).

29. Sessler, J. L. \& Davis, J. M. Sapphyrins: Versatile anion binding agents. Acc. Chem. Res. 34, 989-997 (2001).

30. Brooks, S. J., Gale, P. A. \& Light, M. E. Anion-binding modes in a macrocyclic amidourea. Chem. Commun. 41, 4344-4346 (2006).

31. Bondy, C. R., \& Loeb, S. J. Amide based receptors for anions. Coord. Chem. Rev. 240, 77-99 (2003).

32. Kang, S. O., Begum, R. A. \& Bowman-James, K. Amide-based ligands for anion coordination. Angew. Chem. Int. Ed. 45, $7882-7894$ (2006).

33. Choi, K. H. \& Hamilton, A. D. Selective anion binding by a macrocycle with convergent hydrogen bonding functionality. J. Am. Chem. Soc. 123, 2456-2457 (2001).

34. te Velde, G. et al. Chemistry with ADF. J. Comput. Chem. 22, 931-967 (2001).

35. Cao, R. K., Rossdeutcher, R. B., Wu, X. X. \& Gong, B. Oligo(5-amino- $N$-acylanthranilic acids): Amide bond formation without coupling reagent and folding upon binding anions. Org. Lett. 22, 7496-7501 (2020).

462 36. http://app.supramolecular.org/bindfit/ 
37. Chang, K. J., Kang, B. N., Lee, M. H. \& Jeong, K. S. Oligoindole-based foldamers with a helical conformation induced by chloride. J. Am. Chem. Soc. 127, 12214-12215 (2005)

38. Juwarker, H., Lenhardt, J. M., Pham, D. M., \& Craig, S. L. 1, 2, 3-triazole $\mathrm{CH} \cdots{ }^{\circ} \mathrm{Cl}^{-}$contacts guide anion binding and concomitant folding in 1, 4-diaryl triazole oligomers. Angew. Chem. Int. Ed. 47, 3740-3743 (2008).

39. Hua, Y. R., Liu, Y., Chen, C. H. \& Flood, A. H. Hydrophobic collapse of foldamer capsules drives picomolarlevel chloride binding in aqueous acetonitrile solutions. J. Am. Chem. Soc. 135, 14401-14412 (2013)

40. Shang, J. et al. Aromatic triazole foldamers induced by $\mathrm{C}-\mathrm{H} \cdots \mathrm{X}(\mathrm{X}=\mathrm{F}, \mathrm{Cl})$ intramolecular hydrogen bonding. J. Org. Chem. 79, 5134-5144 (2014).

41. Juwarker, H. et al. Anion binding of short, flexible aryl triazole oligomers. J. Org. Chem. 74, 8924-8934 (2009).

42. Rekharsky, M., Inoue, Y., Tobey, S., Metzger, A. \& Anslyn, E. Ion-pairing molecular recognition in water: Aggregation at low concentrations that is entropy-driven. J. Am. Chem. Soc. 124, 14959-14967 (2002).

43. Pike, S. J., Hutchinson, J. J. \& Hunter, C. A. H-Bond acceptor parameters of anions. J. Am. Chem. Soc. 39, 6700-6706 (2017).

44. Laurence, C. \& Berthelot, M. Observations on the strength of hydrogen bonding. Perspect. Drug Discov. Des. 18, 39-60 (2000).

45. Gale, P. A., Davis, J. T. \& Quesada, R. Anion transport and supramolecular medicinal chemistry. Chem. Soc. Rev. 46, 2497-3519 (2017).

46. Mindell, J. \& Maduke, M. ClC chloride channels. Genome Biol. 2, reviews3003 (2001).

47. Jentsch, T. J., Maritzen, T. \& Zdebik, A. A. Chloride channel diseases resulting from impaired transepithelial transport or vesicular function. J. Clin. Invest. 115, 2039-2046 (2005)

48. Shen, Y. et al. Ultrasensitive liposome-based assay for the quantification of fundamental ion channel properties. Anal. Chim. Acta 1112, 8-15 (2020).

49. Bartlett, P. \& Marlowe, C. Phosphonamidates as transition-state analog inhibitors of thermolysin. Biochemistry 22, 4618-4624 (1983).

50. Pollack, S. J., Jacobs, J. W. \& Schultz, P. G. Selective chemical catalysis by an antibody. Science 234, 15701573 (1987).

\section{Acknowledgements}

We acknowledge the American Chemical Society - Petroleum Research Fund (PRF\#58364-ND7 to B. G.) for financial support and the US National Science Foundation (CHE-1905094 and 2018160 to B. G. and CHE-2108597

to D. P. M.) for partial financial support. Z.F.S. is supported by K. C. Wong Education Foundation (H. K.), National Key R\&D Program of China (2018YFC1003500) and NSFC (81627801).

\section{Author contributions}

R.K.C. and R.B.R. designed and conducted the syntheses, and also performed the binding studies. Y.S., Y.L.Z., R.B.R., and Z.F.S. performed the vesicle-based assays on anion transport. R.K.C. carried out the ester amidation reactions. X. X. W. processed the X-ray data. D.P.M., L.S.S.B., K.R., and E.Z. performed the computational studies. T.S. helped with the NMR experiments. B.G. conceived and supervised the project. Z.F.S. and B.G. co-wrote the paper. All authors participated in discussion and editing of the manuscript.

\section{Additional information}

Supplementary information and chemical compound information are available in the online version of the paper. Correspondence and requests for materials should be addressed to B.G. 


\section{Competing interests}

508 The authors declare no competing interests.

509 B. G. is a named inventor on a patent application (US PCT patent application PCT/US2021/050041) filed by The

510 Research Foundation for the State University of New York on the anion-binding method described in this work.

511

\section{Data Availability statement}

513 Single-crystal X-ray structure data for macrocycle c5c (CCDC reference number: 2124841) can be obtained free of

514 charge from the Cambridge Crystallographic Data Centre at www.ccdc.cam.ac.uk/data request/cif. All other data

515 generated or analysed during this study are included in this article and its supplementary information files.

516

517 
518 Graphical abstract

519

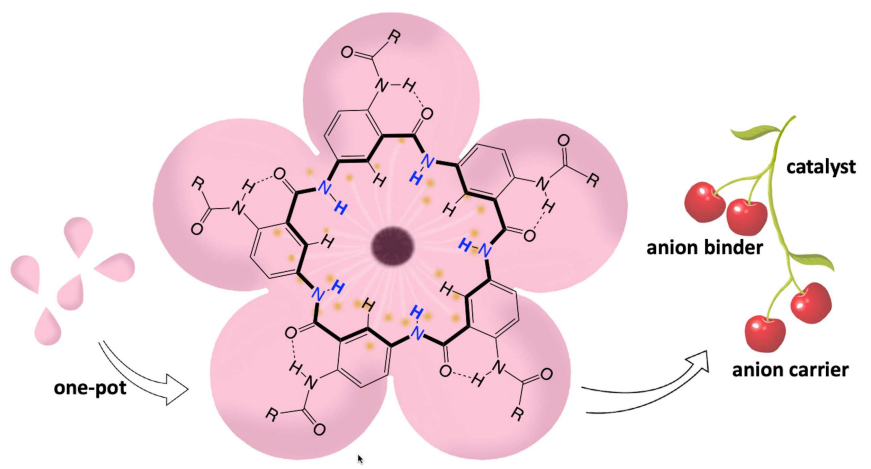




\section{Supplementary Files}

This is a list of supplementary files associated with this preprint. Click to download.

- Suppllnfo.pdf

- checkcif.pdf

- Rrc1abs.cif 